\title{
(6) OPEN ACCESS \\ The impact of HIV and antiretroviral therapy on TB risk in children: a systematic review and meta-analysis
}

\author{
P J Dodd, ${ }^{1}$ A J Prendergast, ${ }^{2,3}$ C Beecroft, ${ }^{1}$ B Kampmann, ${ }^{4,5}$ J A Seddon ${ }^{4}$
}

- Additional material is

published online only. To view please visit the journal online (http://dx.doi.org/10.1136/ thoraxinl-2016-209421).

'School of Health and Related Research, University of Sheffield, Sheffield, UK

${ }^{2}$ Blizard Institute, Queen Mary University of London, London, UK

${ }^{3}$ Zvitambo Institute for Maternal and Child Health Research,

Harare, Zimbabwe

${ }^{4}$ Centre of International

Child Health, Department of Paediatrics, Imperial College London, London, UK

${ }^{5}$ Vaccines \& Immunity Theme, MRC Unit The Gambia, The Gambia

Correspondence to Dr PJ Dodd, School of Health and Related Research, Regent Court, 30 Regent Street, Sheffield S1 4DA, UK; p.j.dodd@ sheffield.ac.uk

Received 13 September 2016 Revised 13 December 2016 Accepted 15 December 2016 Published Online First 23 January 2017

\section{ABSTRACT \\ Background Children ( $<15$ years) are vulnerable to TB disease following infection, but no systematic review or meta-analysis has quantified the effects of HIV-related immunosuppression or antiretroviral therapy (ART) on their TB incidence.}

Objectives Determine the impact of HIV infection and ART on risk of incident TB disease in children.

Methods We searched MEDLINE and Embase for studies measuring HIV prevalence in paediatric TB cases ('TB cohorts') and paediatric HIV cohorts reporting TB incidence ('HIV cohorts'). Study quality was assessed using the Newcastle-Ottawa tool. TB cohorts with controls were meta-analysed to determine the incidence rate ratio (IRR) for TB given HIV. HIV cohort data were meta-analysed to estimate the trend in log-IRR versus CD4\%, relative incidence by immunological stage and ART-associated protection from TB.

Results 42 TB cohorts and 22 HIV cohorts were included. In the eight TB cohorts with controls, the IRR for TB was 7.9 (95\% Cl 4.5 to 13.7). HIV-infected children exhibited a reduction in IRR of 0.94 (95\% credible interval: $0.83-1.07)$ per percentage point increase in CD4\%. TB incidence was 5.0 (95\% Cl 4.0 to 6.0) times higher in children with severe compared with non-significant immunosuppression. TB incidence was lower in HIV-infected children on ART (HR: 0.30; 95\% $\mathrm{Cl} 0.21$ to 0.39 ). Following initiation of ART, TB incidence declined rapidly over 12 months towards a HR of 0.10 ( $95 \% \mathrm{Cl} 0.04$ to 0.25$)$.

Conclusions HIV is a potent risk factor for paediatric $T B$, and ART is strongly protective. In HIV-infected children, early diagnosis and ART initiation reduces TB risk.

Trial registration number CRD42014014276.

\section{INTRODUCTION}

Children are at high risk of progression to $\mathrm{TB}$ disease following infection with Mycobacterium tuberculosis, particularly children in the first 2 years of life, who often develop non-pulmonary forms of TB. ${ }^{1}$ The variety of presentation, difficulty in obtaining samples for laboratory testing and paucibacillary nature of disease mean that confirming a TB diagnosis in children can be challenging. This adds to difficulties in understanding the natural history and epidemiology of disease. Recent indirect approaches to burden estimation have used mathematical modelling of exposure and disease progression risks to predict paediatric $\mathrm{TB}$

\section{Key messages}

What is the key question?

- What effects do HIV infection and antiretroviral therapy (ART) have on TB risk in children?

What is the bottom line?

- HIV infection increases the incidence of TB in children by a factor of around 8 , increasing with degree of immunosuppression; ART reduces TB risk by around $70 \%$, with protection continuing to increase over $1-2$ years.

\section{Why read on?}

- TB incidence in HIV-infected children is very high, but no systematic review has quantified the effects of HIV or ART on TB risk in children.

incidence. $^{2}$ WHO estimated that in 2014, 1 million children developed TB globally. ${ }^{3}$

Although programmes to prevent mother-to-child transmission (PMTCT) of HIV have reduced new cases of vertically infected infants, coverage is incomplete; in 2013, an estimated 199000 (170 000-230 000) children were newly infected with $\mathrm{HIV}^{4}$ Children experience more rapid HIV disease progression than adults, making them highly susceptible to opportunistic infections. ${ }^{5}$ Antiretroviral therapy (ART) can restore immune function and has enormously reduced morbidity and mortality among HIV-infected children. In 2015, WHO guidelines were revised, recommending all HIV-infected children should initiate ART, irrespective of clinical disease stage or degree of immunosuppression. ${ }^{6}$ However, ART coverage among children lags behind adults, with only one-third of eligible children currently on ART compared with two-thirds of adults. ${ }^{4}$

In adults, HIV is a known potent risk factor for developing $\mathrm{TB}$, with incident rate ratios (IRR) $>5$ when averaged across all levels of immunodeficiency. ${ }^{7}$ Evidence synthesis suggests an exponential increase in the IRR with decrease in CD4 T-cell counts. ${ }^{8}{ }^{9}$ The effect of ART in reducing TB risk in adults living with HIV infection is well described. ${ }^{10}$ This quantitative understanding of the effects of HIV and ART on TB progression has been widely used by modellers, for example, in predicting the
Prendergast $A J$

Beecroft $\mathrm{C}$, et al. Thorax 2017:72:559-575. 
impact of HIV interventions on TB incidence. ${ }^{9} 1112$ In contrast to adults, the impact of HIV infection and ART on TB progression in children is poorly quantified; no systematic reviews have been performed to evaluate this relationship. In the context of revised WHO treatment recommendations, our objective was therefore to systematically review the paediatric HIV/TB literature to quantify the effect of HIV and ART on TB risk in children.

\section{METHODS}

This systematic review is reported in accordance with the Preferred Reporting Items for Systematic Review and Meta-Analyses statement ${ }^{13}$ (see online supplementary material). A protocol was registered with PROSPERO (identification number: CRD42014014276) in October 2014.

\section{Cohort definitions}

For all studies, the exposure/intervention was HIV infection, with or without ART. We sought studies that either: (i) reported HIV prevalence in children with TB ('TB cohorts') or (ii) reported TB disease incidence in cohorts of children with HIV ('HIV cohorts'). For TB cohorts, the outcome was HIV prevalence, and the comparator was HIV prevalence in control groups of children without TB. For HIV cohorts, the outcome was TB incidence, and the comparison was between subgroups of the same cohort with different levels of immune suppression, or ART exposure (all HIV-infected).

\section{Search strategy, selection criteria, data extraction}

To be eligible, a study had to present empirical data on more than five cases of TB in children (aged $<15$ years). Studies were excluded if they were not generally representative of paediatric TB cases in that population at that time, for example, studies that only addressed one form of TB; that only comprised hospitalised TB cases; studies explicitly focused on migrant populations or autopsy studies. If the same cohort was published more than once, or individuals were described in more than one cohort, studies/children were only included once. Where explicit use of isoniazid preventive therapy (IPT) was stated, children receiving IPT were excluded. TB cohorts were excluded if the coverage of HIV testing was below $70 \%$ among TB cases. HIV cohorts were excluded if data were not reported that could be interpreted as an incidence (ie, number of events and person-time).

MEDLINE and Embase were systematically searched without language, publication or date restrictions using terms designed to capture children and TB and (HIV or ART) on 20 December 2014 (see online supplementary material for full search). A combination of MeSH and EMTREE headings were used with free-text terms to enhance the sensitivity of the search. We further searched the Cochrane Controlled Trials Register and AIDSinfo for relevant studies. All references in review articles found by our database search were included. All citations listed in Google Scholar of the five most cited review articles found by our database search were screened. One additional study in press at the time of our systematic review was brought to our attention after presenting draft results. ${ }^{14}$ Two investigators (PJD and JAS) independently assessed titles and abstracts for inclusion. Full texts were independently assessed for inclusion and study type by PJD and JAS with disagreements resolved by discussion. Two investigators extracted the data for TB cohorts in tandem; PJD extracted the data for HIV cohorts with $25 \%$ of data checked by JAS.
For both study designs, the following were recorded: first author, publication year, study years, study country, number of TB cases, age range, number of male children. For TB cohorts, if local TB-free controls were reported in the study, the HIV prevalence among control children (numerator and denominator) was extracted. Other data extracted from the TB cohorts included: the coverage of HIV testing, the numerator and denominator of HIV prevalence in TB cases and the UNAIDS paediatric HIV estimate for corresponding country-year (if available; mid-point and uncertainty range). For HIV cohorts, the following were recorded: TB incidence (with uncertainty range), ART coverage at enrolment, estimate of protective effect of ART against TB (if present) and TB incidence in any ART-related or immune-related stratum (with uncertainty range). Co-trimoxazole use was recorded where described. TB incidence by age band was extracted if present. Some studies recorded immune status using the WHO immunological classification ${ }^{6}$ (not-significant, mild, advanced and severe immunosuppression), whereas others used alternative CD4\% or CD4 count categories, which differed between studies. Mid-points and CIs (assumed Poisson exact) were used to infer event numbers and person-time when aggregation was necessary. Some studies excluded incident TB within the first few months on ART, stating that they sought to exclude immune reconstitution inflammatory syndrome reactions and only determine true TB incidence.

Quality of individual studies was assessed using an adapted Newcastle-Ottawa quality assessment tool. ${ }^{15}$ The version for case-control studies was used for TB cohorts; the version for cohort studies for HIV cohorts. For HIV cohorts, the quality for each study as input to each meta-analysis was assessed separately (see online supplementary material pp. 18-21) and reported as low/moderate/high quality (depending on whether few/some/most criteria were met) on domains of selection, comparability and either outcome (for cohort studies) or exposure (for case-control studies).

\section{Statistical analyses}

For TB cohorts, we undertook a random-effects meta-analysis of the OR for HIV prevalence given TB among those studies reporting HIV prevalence in controls. This OR can be interpreted as an IRR for developing TB disease if HIV positive ${ }^{7}$ (see online supplementary material p. 7). We produced funnel plots to assess evidence of publication bias.

For TB cohorts where UNAIDS estimates of national HIV prevalence in the age group aged $<15$ years were available for the same year and country as the study, we undertook a Bayesian meta-analysis using both the UNAIDS data and control data. This analysis modelled the relationship between UNAIDS HIV prevalence and HIV prevalence in study controls from studies where both were available, and used this relationship to predict individual study ORs where controls were not available. For comparison, a Bayesian version of the meta-analysis of studies with controls was conducted (see online supplementary material pp. 8-11).

For HIV cohorts reporting TB incidence by immune stage, we undertook a random-effects meta-analysis of the IRR for each stratum relative to the 'not-significant' WHO immune stage. For HIV cohorts reporting incidence by $>1$ CD $4 \%$ category (using the mid-point of the CD4\% category in which the incidence was reported), or an analysis of the relation between CD4\% and IRR for TB, we undertook a Bayesian meta-analysis to estimate the gradient of logarithmic IRR with respect to CD4\% (see online supplementary material pp. 13-15). We averaged the IRR 
implied by this point estimate over CD4\% between $0 \%$ and $50 \%$ to compare with our IRR from the TB cohort analysis. For HIV cohorts reporting an estimate of the protection against TB from ART as a HR, we performed a random-effects meta-analysis. For HIV cohorts reporting TB incidence by $>1$ category of time-since-ART-initiation, we fitted a non-linear mixed-effects model to estimate the temporal dependence of ART protection, using the mid-point of the time window in which the incidence was reported to model incidence (see online supplementary material pp. 15-16).

Bayesian techniques were employed where greater flexibility was required over standard software implementations to use all the data. All statistical analyses were undertaken using $\mathrm{R}$ statistical software (R Core Team. R: A language and environment for statistical computing. $\mathrm{R}$ Foundation for Statistical Computing, Vienna, Austria. URL http://www.R-project.org); random-effects meta-analysis was performed using the rma command in the metafor package implementing the restricted maximum-likelihood estimator. ${ }^{16}$

\section{RESULTS}

\section{Search results}

The systematic review process is presented in figure 1 . Of the 311 full-text articles screened, 65 were included in this review. The most common reasons for exclusion were HIV test coverage $<70 \%$ for TB cohorts $(\mathrm{n}=46)$ and TB incidence not reported for HIV cohorts $(n=22)$. Of the 65 included studies, 42 were classified as TB cohorts (see table 1), 22 were classified as HIV cohorts (see table 2) and 1 study included both a TB and HIV cohort. ${ }^{17}$ Thirty-one of the $42 \mathrm{~TB}$ cohorts (74\%) and 17 of the 22 HIV cohorts (77\%) were from sub-Saharan Africa.

Of the TB cohorts, 8 included HIV prevalence in controls without $\mathrm{TB}$ and could be used in the random-effects meta-analysis; 35 had relevant UNAIDS estimates and could be included in the Bayesian meta-analysis, including all 8 studies with controls.

Of the HIV cohorts, 7 could be included in the meta-analysis of CD4\% influence, 3 could be included in the analysis of the influence of immunological staging, 10 were included in the analysis of time on ART and 6 were included in the pooled estimate of ART efficacy against TB. Only three HIV cohorts reported co-trimoxazole use. ${ }^{14} 6780$

HIV prevalence in TB cohorts ranged between 5\% and 94\% (see online supplementary material p. 5). TB incidence in HIV cohorts ranged from 0.3 to 25.3 per 100 person-years (see online supplementary material p. 6). Insufficient data were available in either group of cohorts to stratify results by age.

\section{Quality assessment}

TB cohorts were of low and moderate quality for our analysis (table 1). Studies without controls could not be classed higher than moderate quality on selection and low quality on exposure. Controls were often drawn from clinic populations in the same context. In around half of studies, TB was defined only by a decision to treat.

HIV cohorts were typically of low quality for our analyses (table 2). Most studies were clinic-based and not necessarily community-representative; prevalent TB was not always ruled out at baseline; there were often shortcomings in follow-up or case definitions for TB.

\section{Meta-analyses for TB cohorts}

The random-effects meta-analysis of TB cohorts for the odds of having HIV in TB cases included eight case-control studies (figure 2). In total, $1215 \mathrm{~TB}$ cases and 1232 non-TB controls were included. The pooled estimate for the OR was $7.9(95 \%$ CI 4.5 to 13.7$)$, and the I-squared heterogeneity statistic $\left(\mathrm{I}^{2}\right)$ was $69.8 \%$ (see figure 2). A funnel plot corresponding to this analysis is presented in online supplementary material p. 8 .

The Bayesian meta-analysis included 35 studies (including all 8 with controls) and produced a pooled estimate of the OR for HIV among children with TB of 7.0 (95\% credible interval (CrI): 5.7-8.5), see figure 3. This analysis also found the paediatric HIV prevalence in controls to be substantially higher than national UNAIDS estimates of HIV prevalence in the age group aged $<15$ years, with an OR of 7.3 (95\% CrI: 5.9 to 8.8 ). For studies that lacked explicit control groups (indicated in red in figure 3), this analysis also predicted what the ORs would have been for HIV prevalence in TB cases versus HIV prevalence in a putative control group of comparable children without TB. The pooled estimates of effect for the analyses with and without the UNAIDS data were similar (see online supplementary material p. 11).

\section{Meta-analyses for HIV cohorts}

For HIV cohorts, the random-effects meta-analysis of TB incidence in children with severe compared with non-significant immunosuppression according to the WHO categorisation gave an IRR of $5.0 \quad\left(95 \%\right.$ CI 4.0 to 6.0 ) with $\mathrm{I}^{2}=87.1 \%$ (see figure 4). The Bayesian meta-analysis of the gradient of the logarithmic IRR with respect to CD4\% yielded a pooled estimate of $-0.063(95 \%$ CrI: -0.188 to +0.063$)$, corresponding to a reduction in IRR of 0.94 (95\% CrI: 0.83 to 1.07$)$ per one percentage-point increase in CD4\% (see figure 5). This point estimate implies a mean IRR of 7.1 over CD4\% ranging between $0 \%$ and $50 \%$. The random-effects meta-analysis of protection from ART yielded a pooled HR estimate of $0.30(95 \%$ CI 0.21 to 0.39 ) with $\mathrm{I}^{2}=79 \%$ (see figure 6 ).

The non-linear mixed-effects regression for the protection from ART by time-since-initiation estimated a rapid initial decline in incidence over the first year, reaching a plateau as protection from ART fully establishes over around 2 years at a pooled asymptotic HR of 0.10 (95\% CI 0.04 to 0.25 ), giving a mean HR over the first 30 months on ART of approximately 0.25 (see figure 7).

\section{DISCUSSION}

In this systematic review, we identified cohorts of children with TB and cohorts of children with HIV. We observed a high but variable prevalence of HIV infection in the TB cohorts, and a very high TB incidence in the HIV cohorts. Accounting for background risk of TB, we found, as in adults, HIV was important risk factor for TB and that TB risk increases with immunosuppression. ART was strongly protective against TB, but took 2 years for full potential of protection against TB to be realised.

In adults, IRRs for TB given HIV around six have been estimated for populations with generalised HIV epidemics, ${ }^{7}$ corresponding to most newly diagnosed adult TB cases having HIV infection. Our IRR for children is comparable, but lower HIV prevalence is seen in children with $\mathrm{TB}$ due to a lower overall paediatric HIV prevalence. In adults, meta-analyses of cohorts of HIV patients suggest exponentially increasing IRR for TB with declining CD4 cell count, ${ }^{9}$ and current CD4 cell counts on ART strongly predict TB incidence. ${ }^{81} \mathrm{~A}$ systematic review and meta-analysis of the protective effect of ART against TB found a HR of $0.35(0.28-0.44)$ across all baseline CD4 cell counts, ${ }^{10}$ comparable to our result for children. Long-term follow-up of adults on ART suggests 4-5 years for protection against TB to 
Figure 1 Preferred Reporting Items for Systematic Review and Meta-Analyses flow chart for systematic review ( ${ }^{*}$ one study included both a TB and HIV cohort $^{17}$ ).

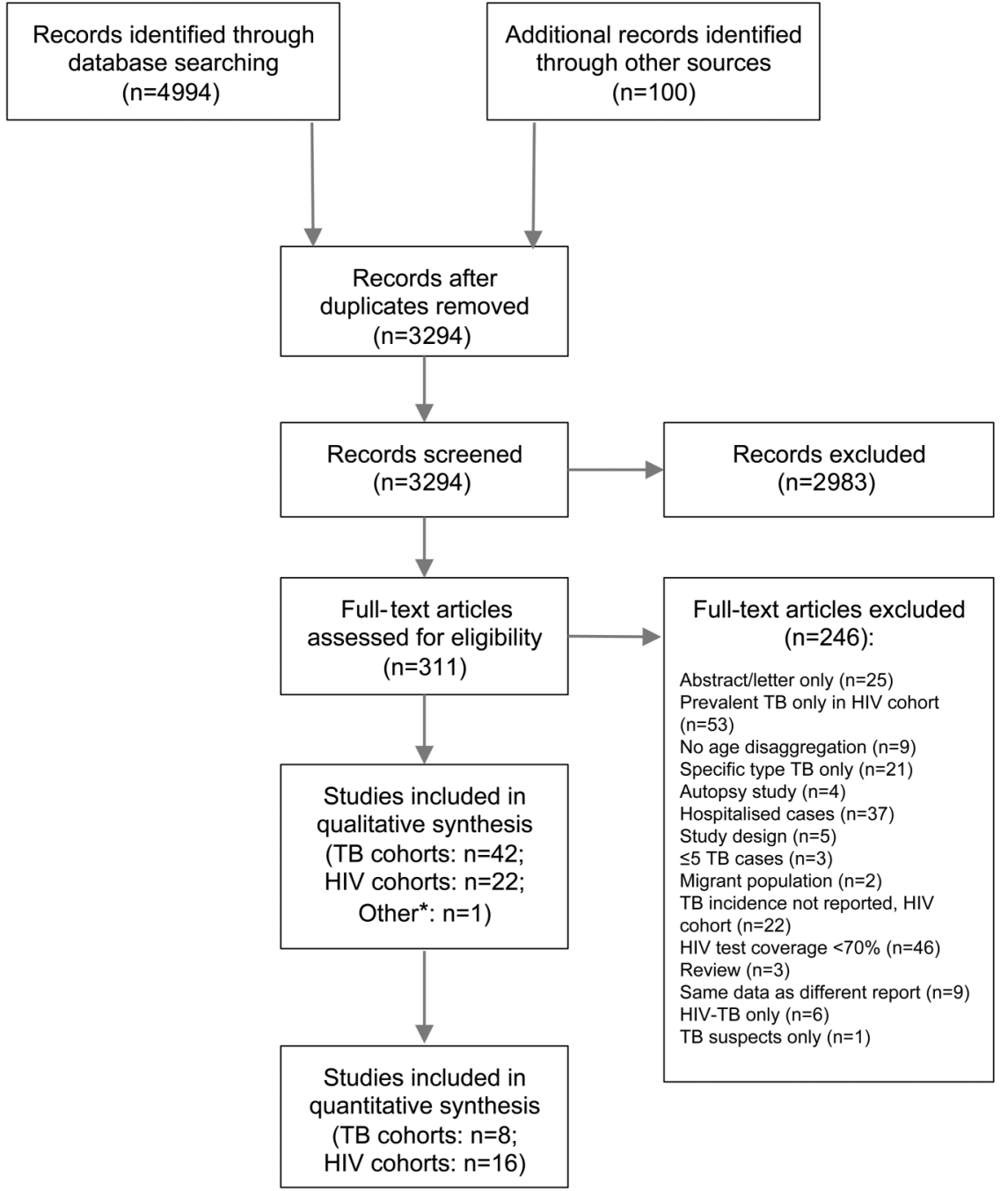

become fully established. ${ }^{82}$ Our analysis suggests that protection against TB in children on ART establishes more rapidly (12 years), consistent with faster CD4 reconstitution among children ${ }^{83}$ compared with adults. ${ }^{84} 85$

Our findings have implications for patient care, guidelines, TB programmes and mathematical modelling. For clinicians, TB risk with HIV and ART informs patient treatment and appropriate family counselling. For TB programme officers, understanding risks informs resource allocation, and service configuration for HIV testing and treatment. These findings can inform evidence-based guideline development; timely given the recent revision of the WHO ART guidelines advocating universal treatment for children with HIV, irrespective of clinical and immunological stage. Finally, these data inform models of burden estimates and for evaluating the impact of interventions, in relation to HIV and ART.

Our review has limitations. Although our search strategy was comprehensive, studies were excluded if not representative of children with TB in that context. The cohorts identified were generally of low quality for our analyses, the most common shortcomings being around population representativeness and TB case-definitions. The majority of studies were from sub-Saharan Africa, where $90 \%$ of all HIV-infected children live, and the findings may not generalise to other regions. The studies spanned a long time period, and may not be representative of the current era. Statistical heterogeneity was high for summary statistics from both TB cohorts and especially HIV cohorts, reflecting diverse study settings and dates, and unreported clinical and methodological heterogeneity. However, measures of heterogeneity were comparable with those from similar studies. ${ }^{86}$ There were a number of limitations of our meta-analyses of TB cohort data. Controls were often not from the general population. This may partially explain the differences between HIV prevalence in study controls and UNAIDS paediatric HIV prevalence estimates. However, UNAIDS reports country-level estimates for children aged $<15$ years, which are not likely to reflect the HIV prevalence in younger children local to these studies. Difficulties in diagnosing TB in children with HIV may have led to differential detection of cases by HIV status, affecting the IRR from case-control TB cohorts. Moreover, estimates of the increased risk of TB progression will be confounded by higher exposure due to sharing households with HIV-infected parents, themselves at increased risk of TB. This makes it difficult to differentiate the direct biological impact of HIV from indirect effects. Implicitly, our analyses assume the same relationship between HIV, ART and TB holds regardless of population TB or HIV prevalence, which may not be the case across the very wide range of prevalences in the studies included.

A number of limitations apply to our meta-analyses of HIV data. CD4\% categories were disparately reported, and we used category mid-points for analyses of CD4\% and time-on-ART. 


\section{节}

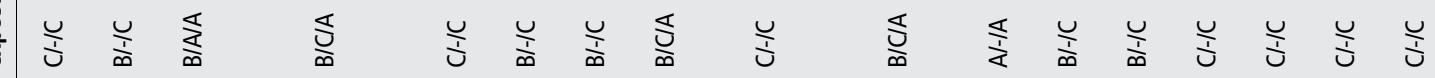

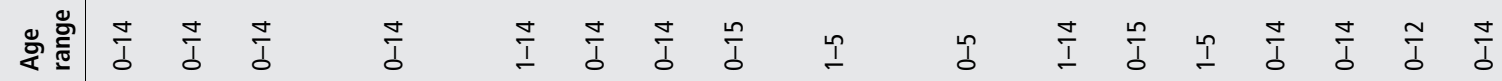
嵩

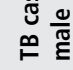

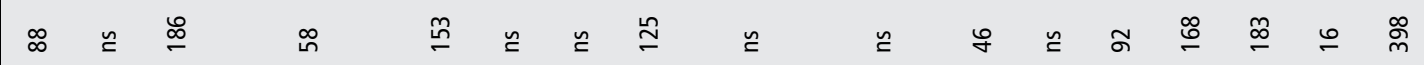
芯

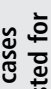

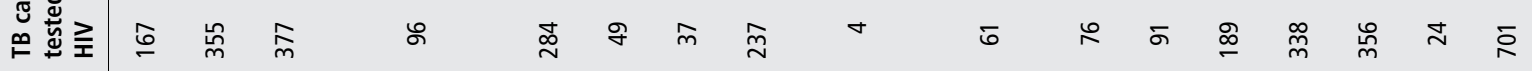

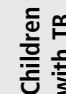

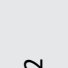

总至

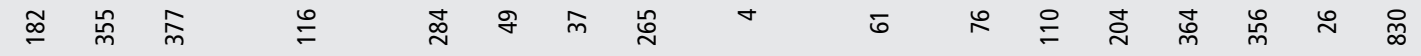

$\stackrel{\circledast}{\simeq} \sim \stackrel{\infty}{=}$

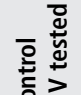

రํำ

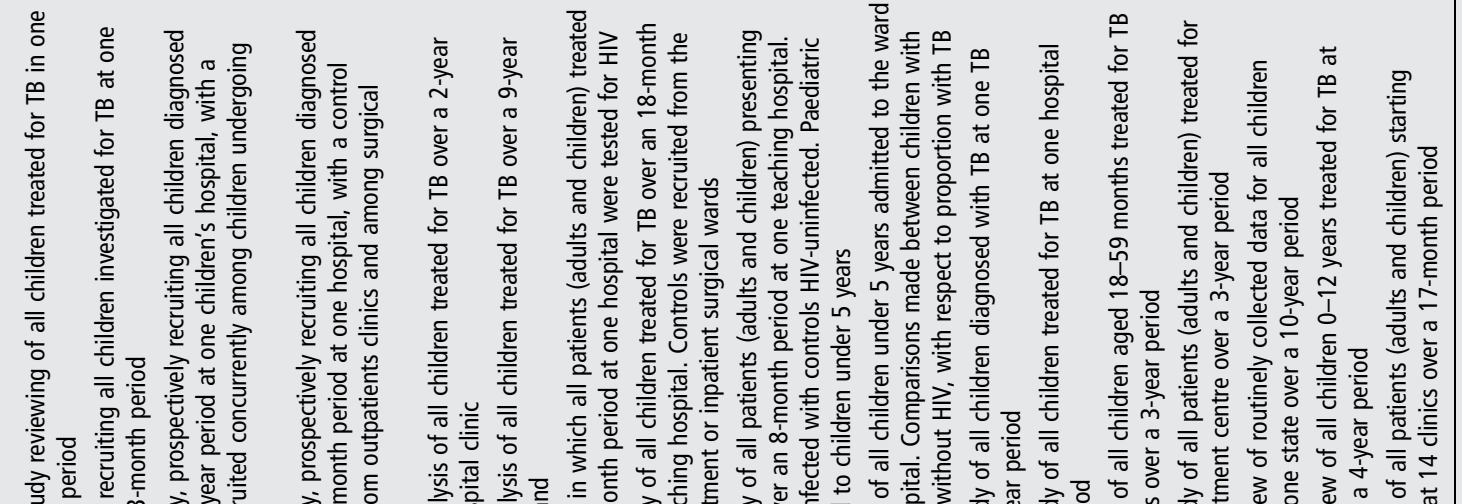

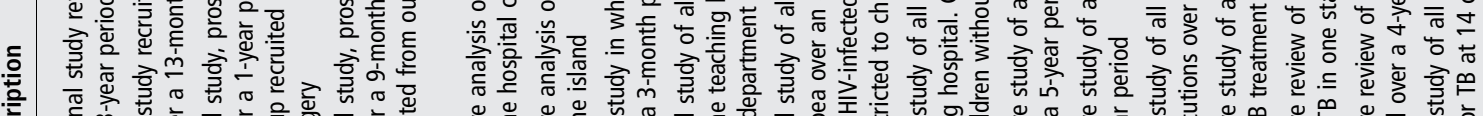

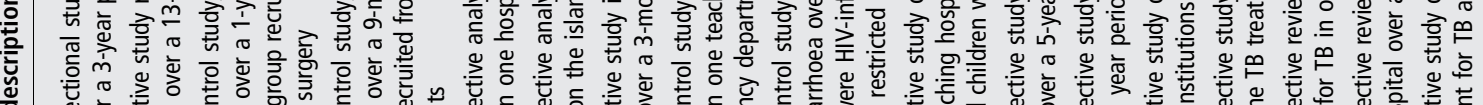

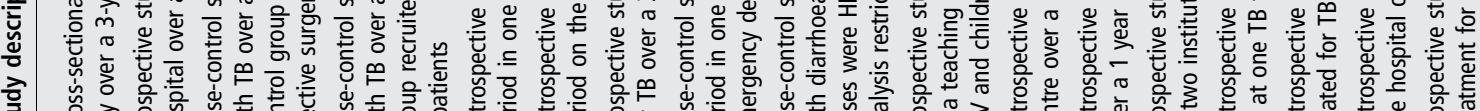

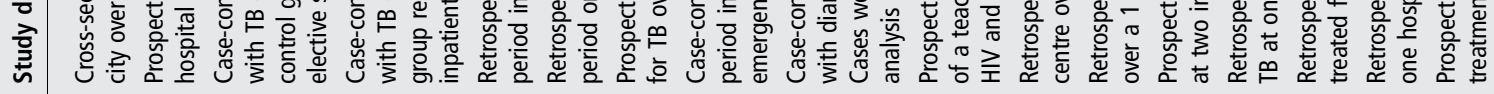

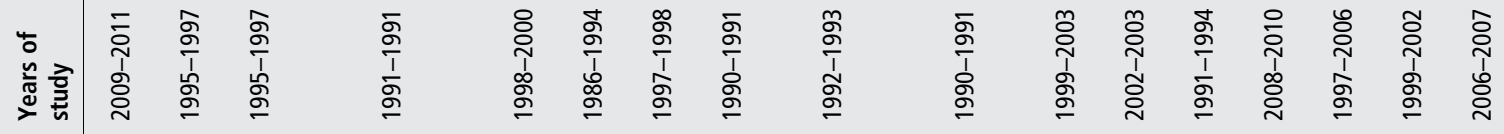

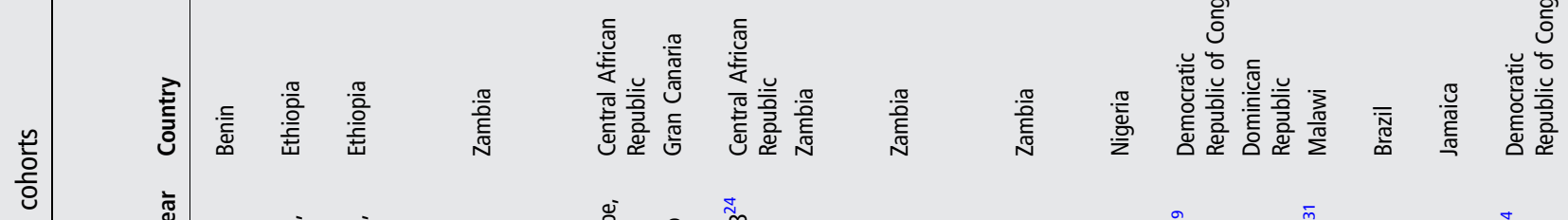

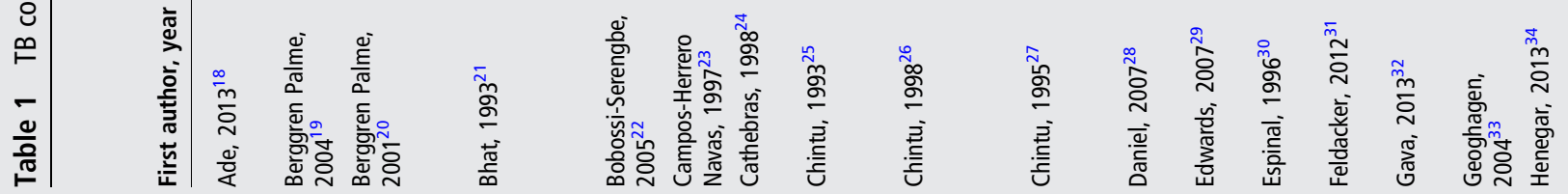




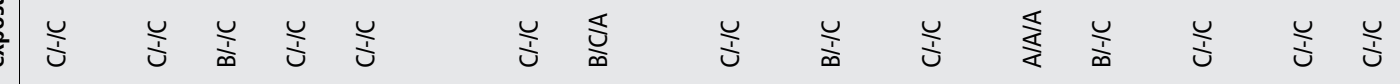

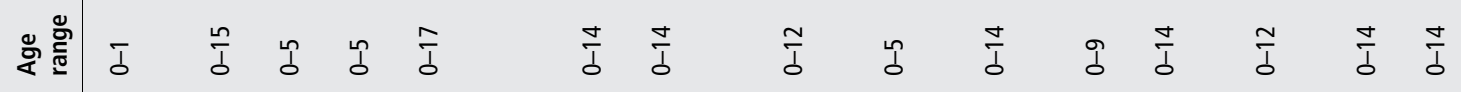
总

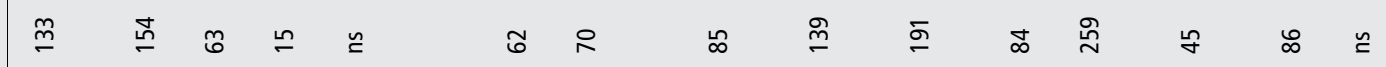
惫主 ๓

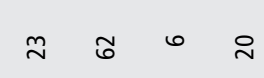

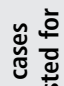

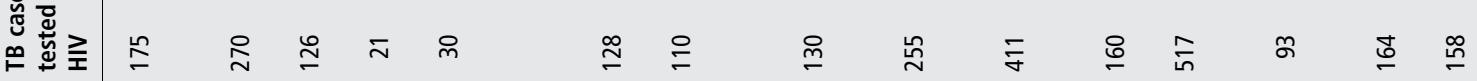

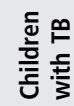

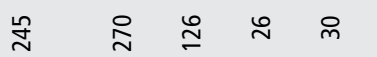

$$
\stackrel{\infty}{\simeq}
$$

$\stackrel{8}{m}$

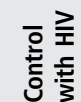
宸 $\stackrel{0}{\simeq}$ $\stackrel{5}{2}$ $\stackrel{2}{2}$ $\stackrel{5}{2}$ $\stackrel{6}{\check{0}}$

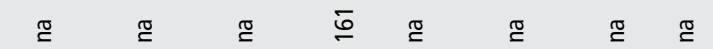

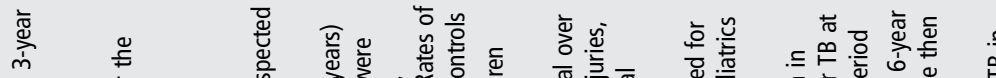

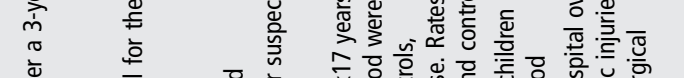

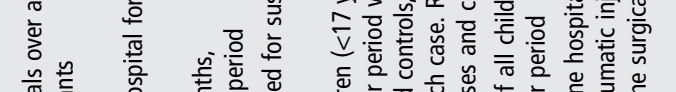

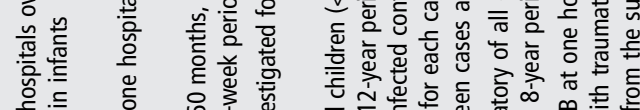

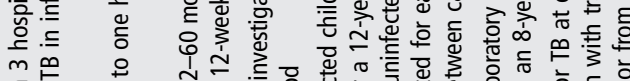

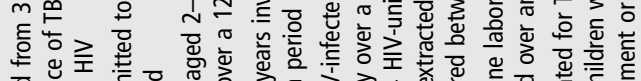

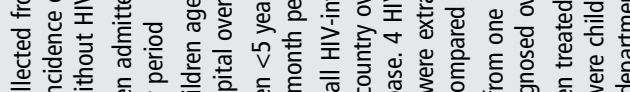

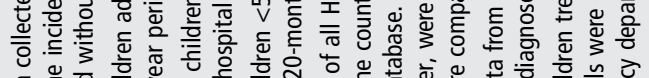

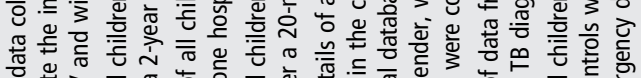

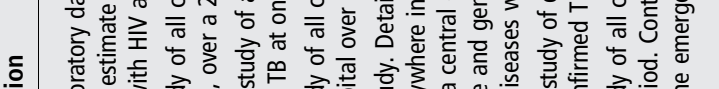

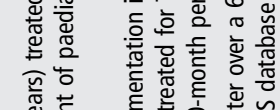
离范 응

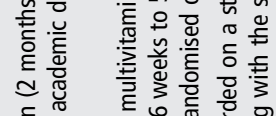

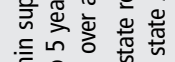

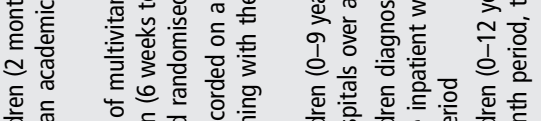
类元 它苟

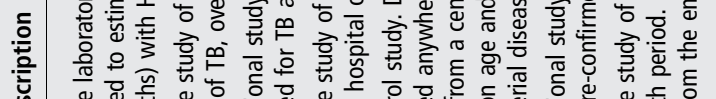
范它

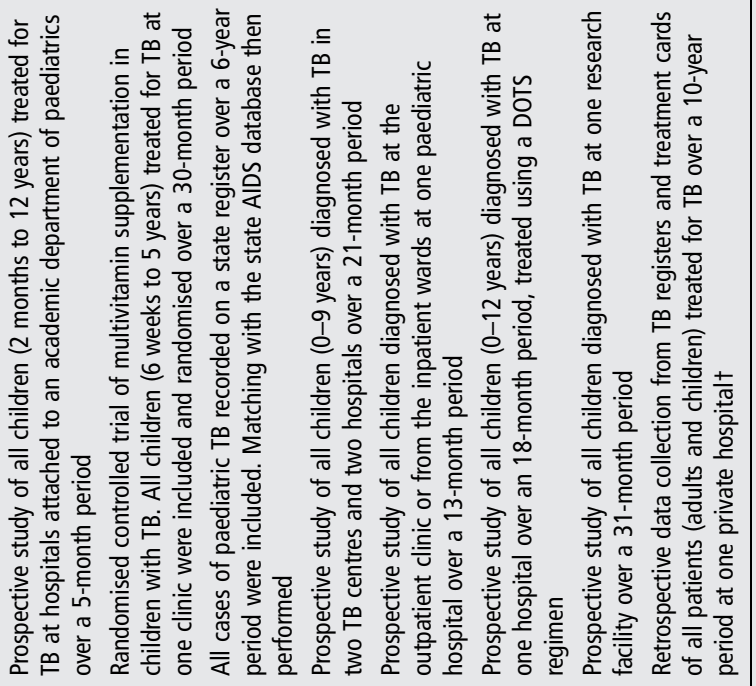

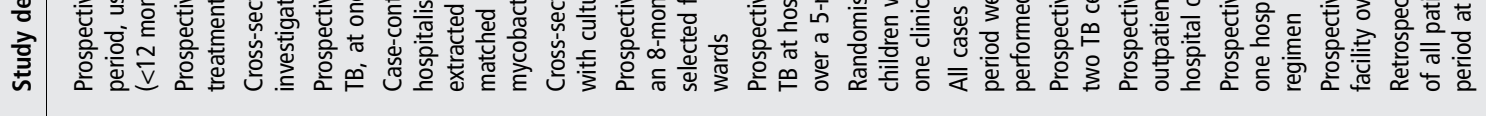

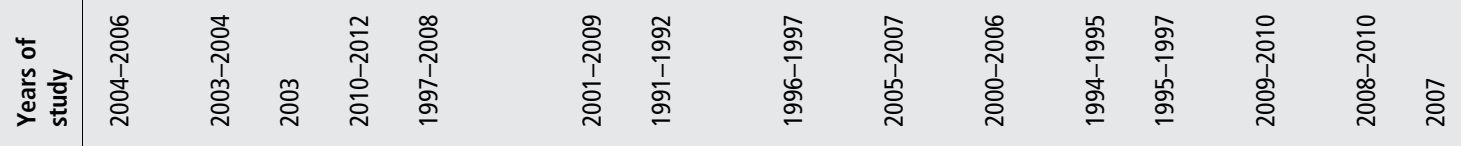




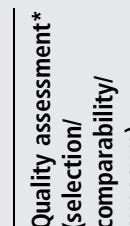

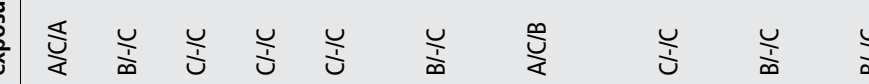

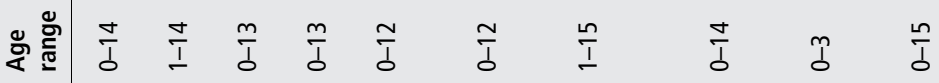

岕

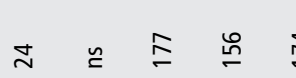

峞

产

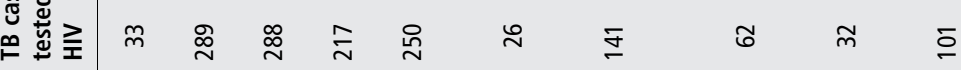

뜰 을

章 $m$

$\stackrel{\circ}{\stackrel{\circ}{\infty}}$

वे

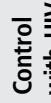

竞

竞离
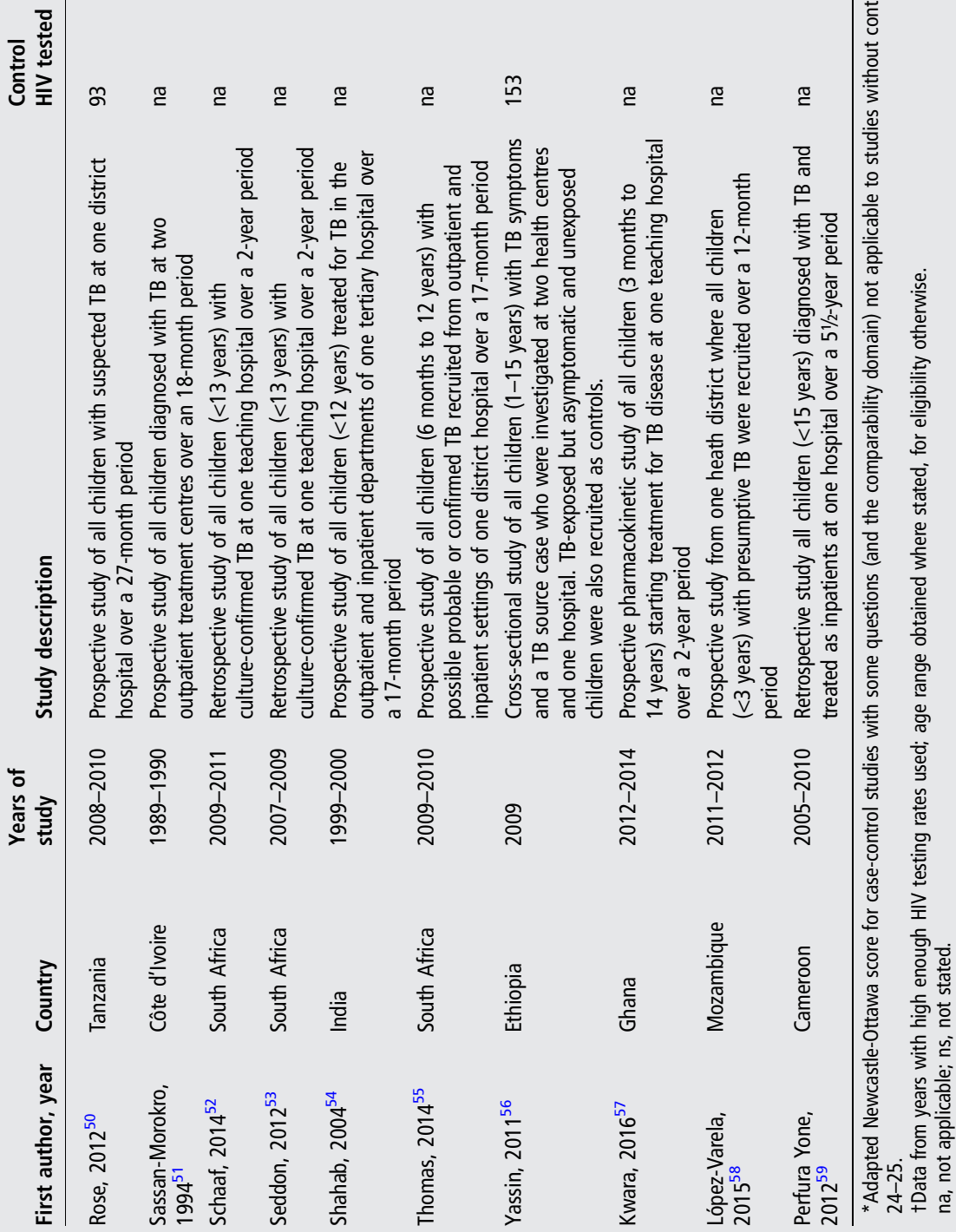


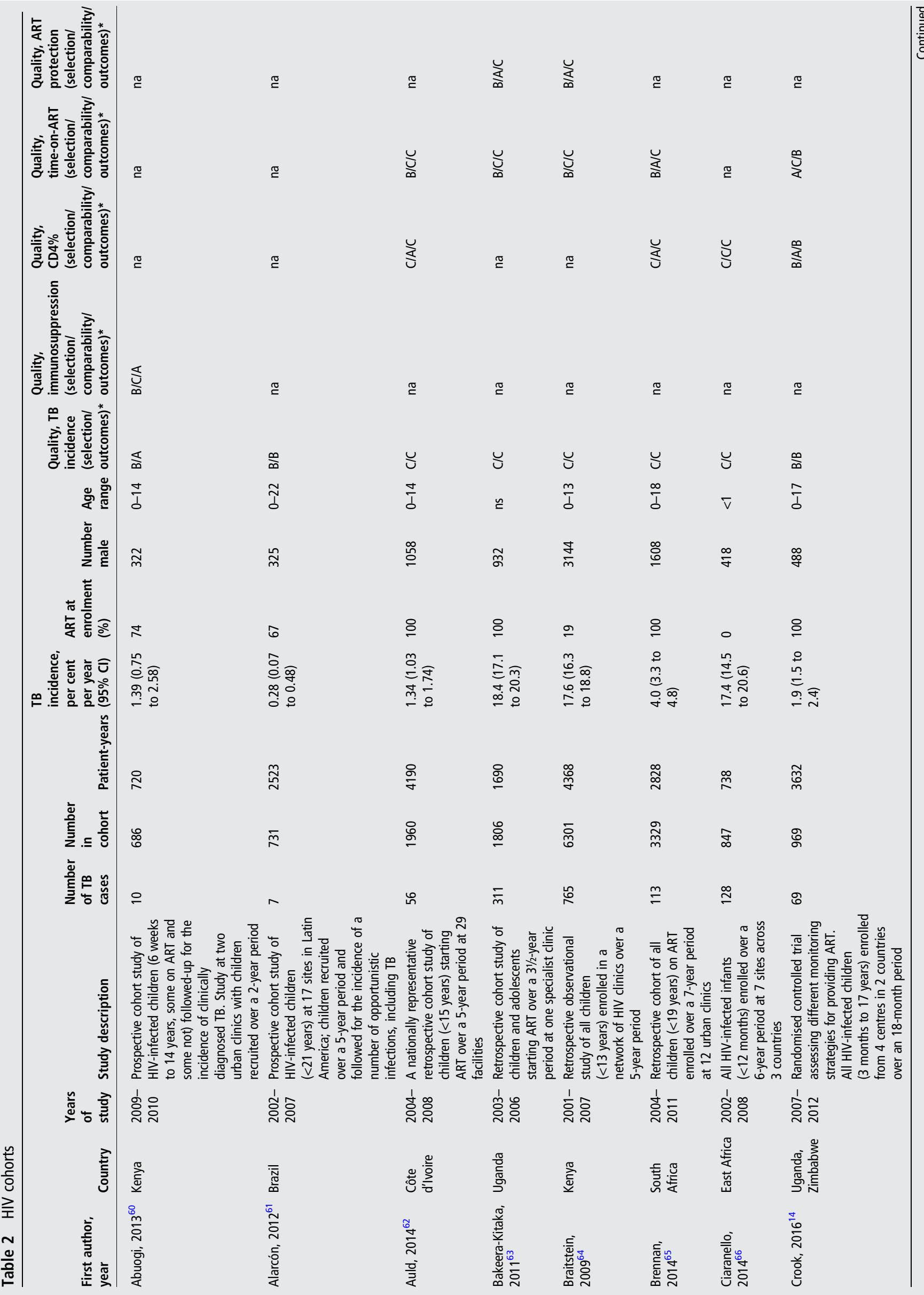




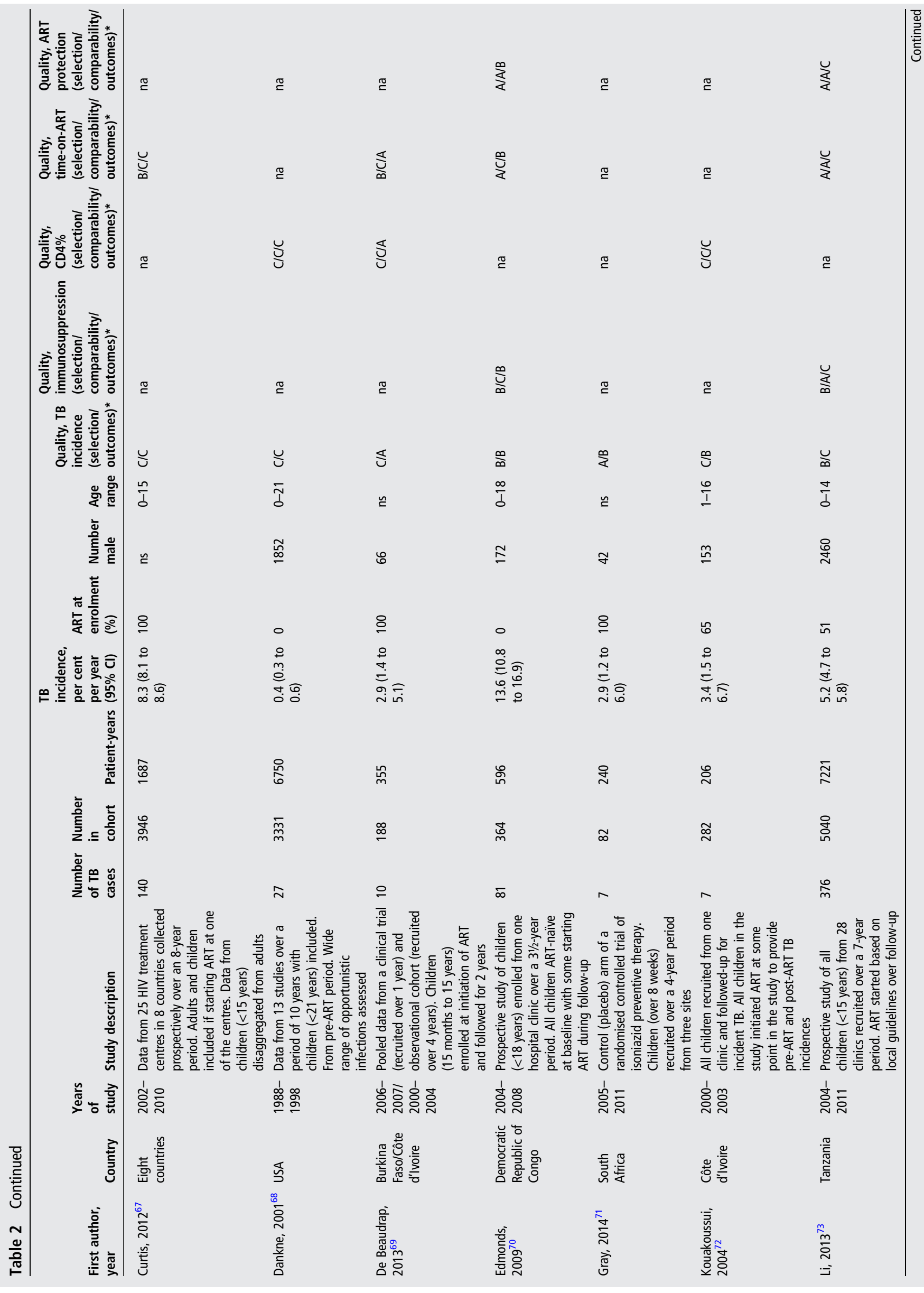




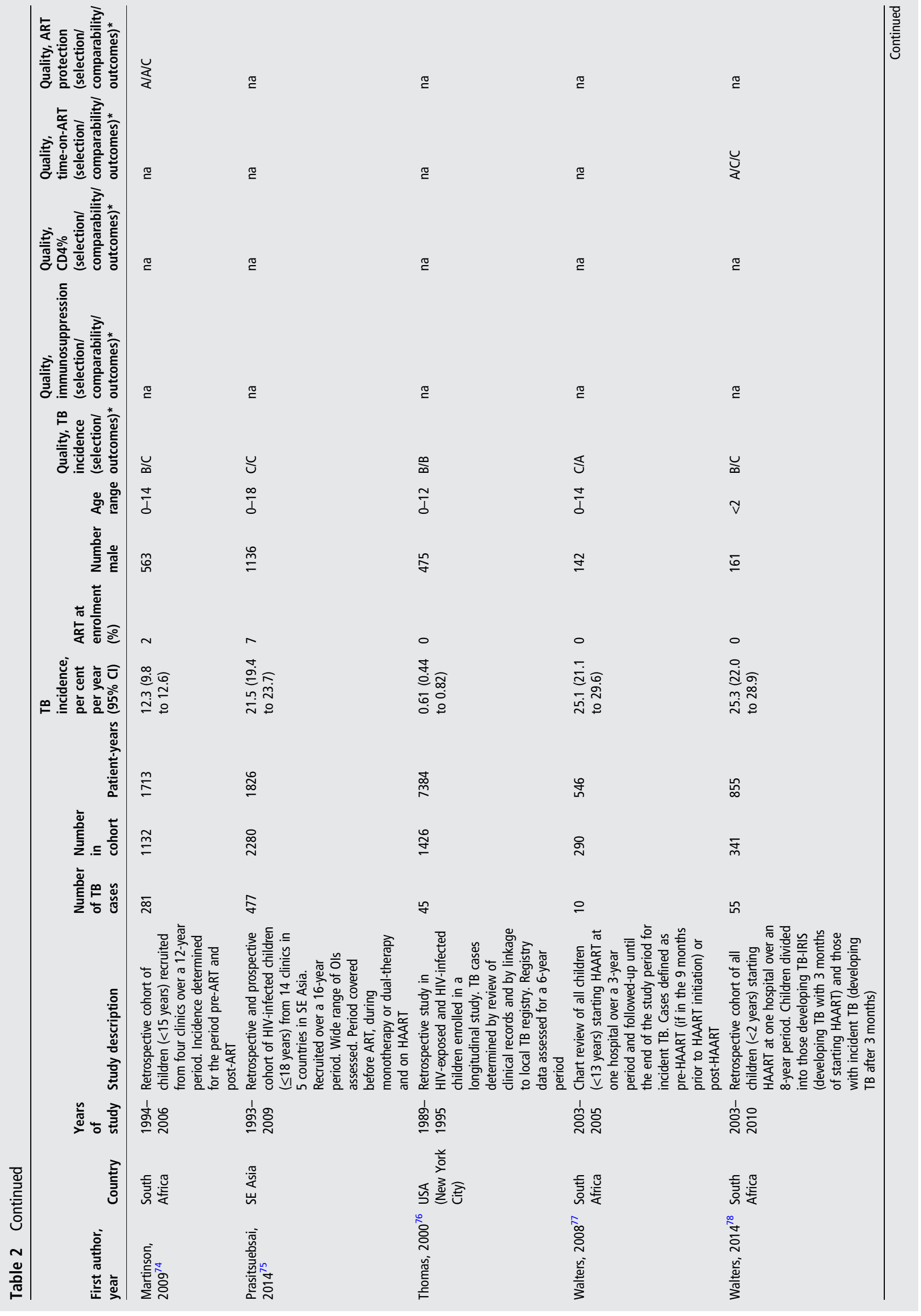

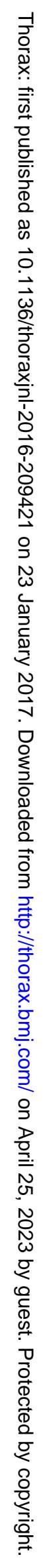




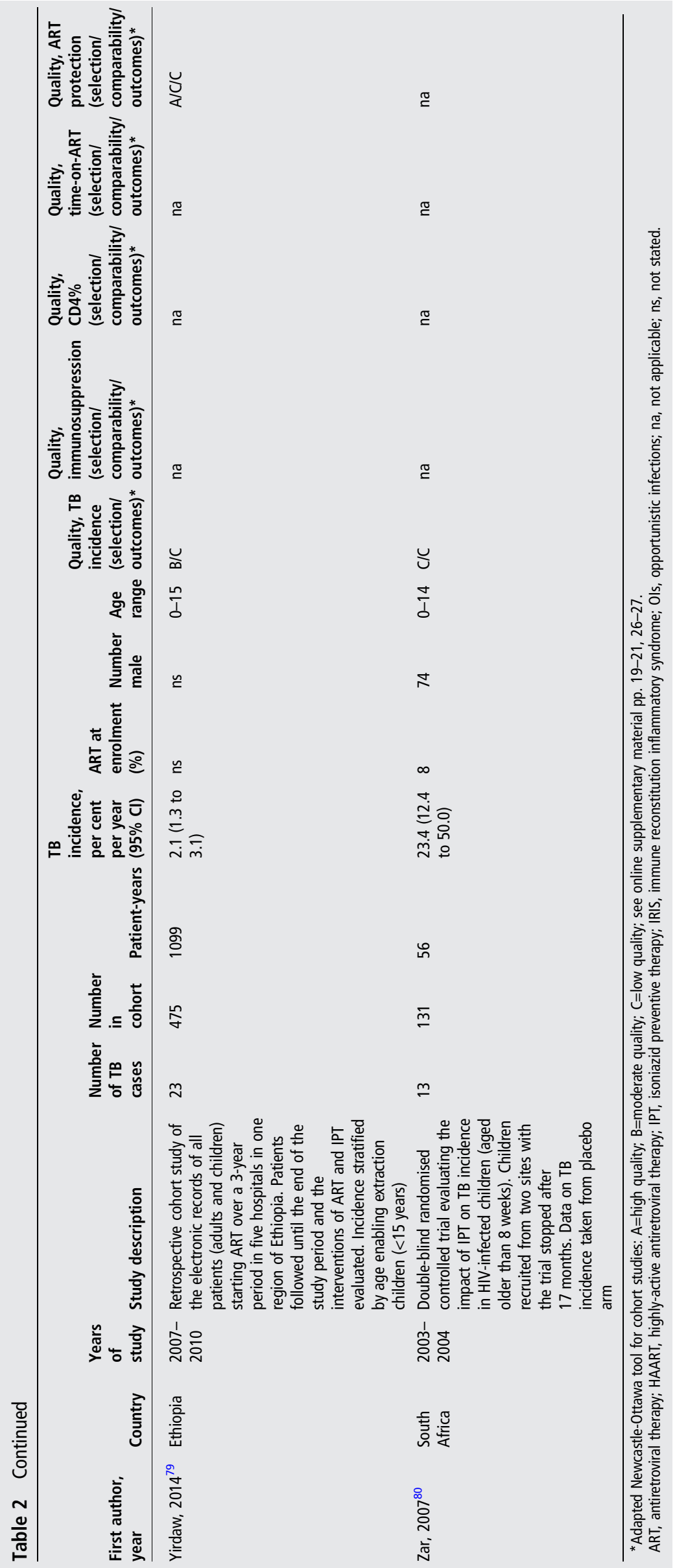




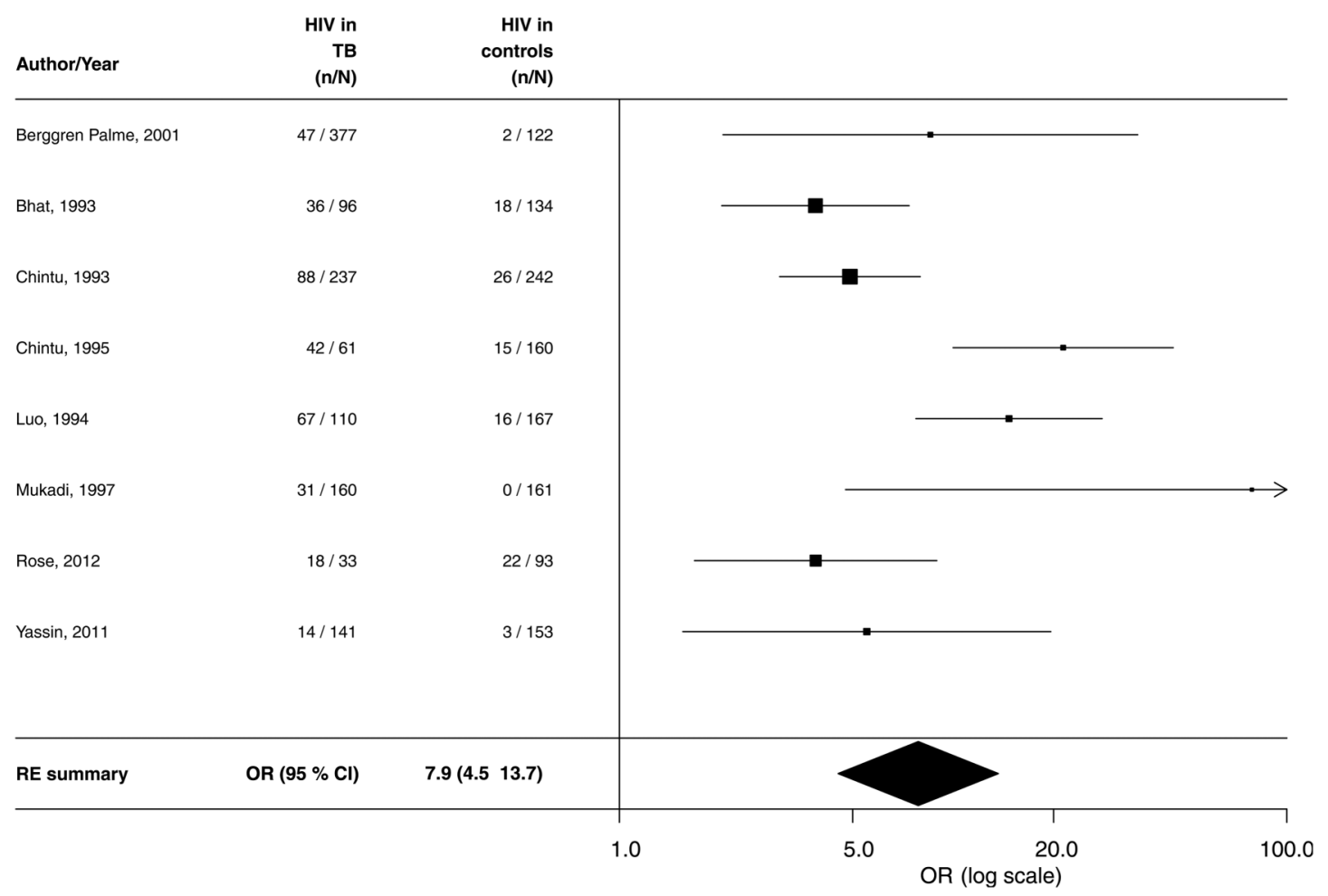

Figure 2 Forest plot for meta-analysis of HIV risk in children aged $<15$ years with prevalent TB-studies with controls $\left(I^{2}=69.8 \%\right)$. RE, random effects.

Figure 3 Forest plot for Bayesian meta-analysis of HIV risk in children aged $<15$ years with prevalent TB. Where studies lacked their own controls, UNAIDS national HIV prevalence data were used to model HIV prevalence in controls based on those studies with both controls and UNAIDS estimates (red). Meta-analyses for studies with controls only are shown in blue; meta-analyses for studies using UNAIDS estimates of paediatric HIV prevalence are shown in red.
Ade, 2013 Berggren Palme, 2004 Berggren Palme, 2001 Bhat, 1993 Bobossi Serengbe, 2005 Cathebras, 1988 Chintu, 1993 Chintu, 1998 Chintu, 1995 Daniel, 2007 Edwards, 2007 Espinal, 1996 -

Feldacker, 2012 Geoghagen, 2004 Henegar, 2013 Hesseling, 2009 Iriso, 2005 Llerena, 2010 Luo, 1994 Madhi, 1999 Mehta, 2011 Miranda, 2011 Mukadi, 1997 Berggren Palme, 2002 Rachow, 2012 Ramos, 2010 Rose, 2012 -

Sassan Morokro, 1994 Schaaf, 2014 Seddon, 2012 Thomas, 2014 Yassin, 2011 Kwara, 2015 Lopez Varela, 2015 Perfura Yone, 2012 SUMMARY -
Analysis

- UNAIDS no UNAIDS 


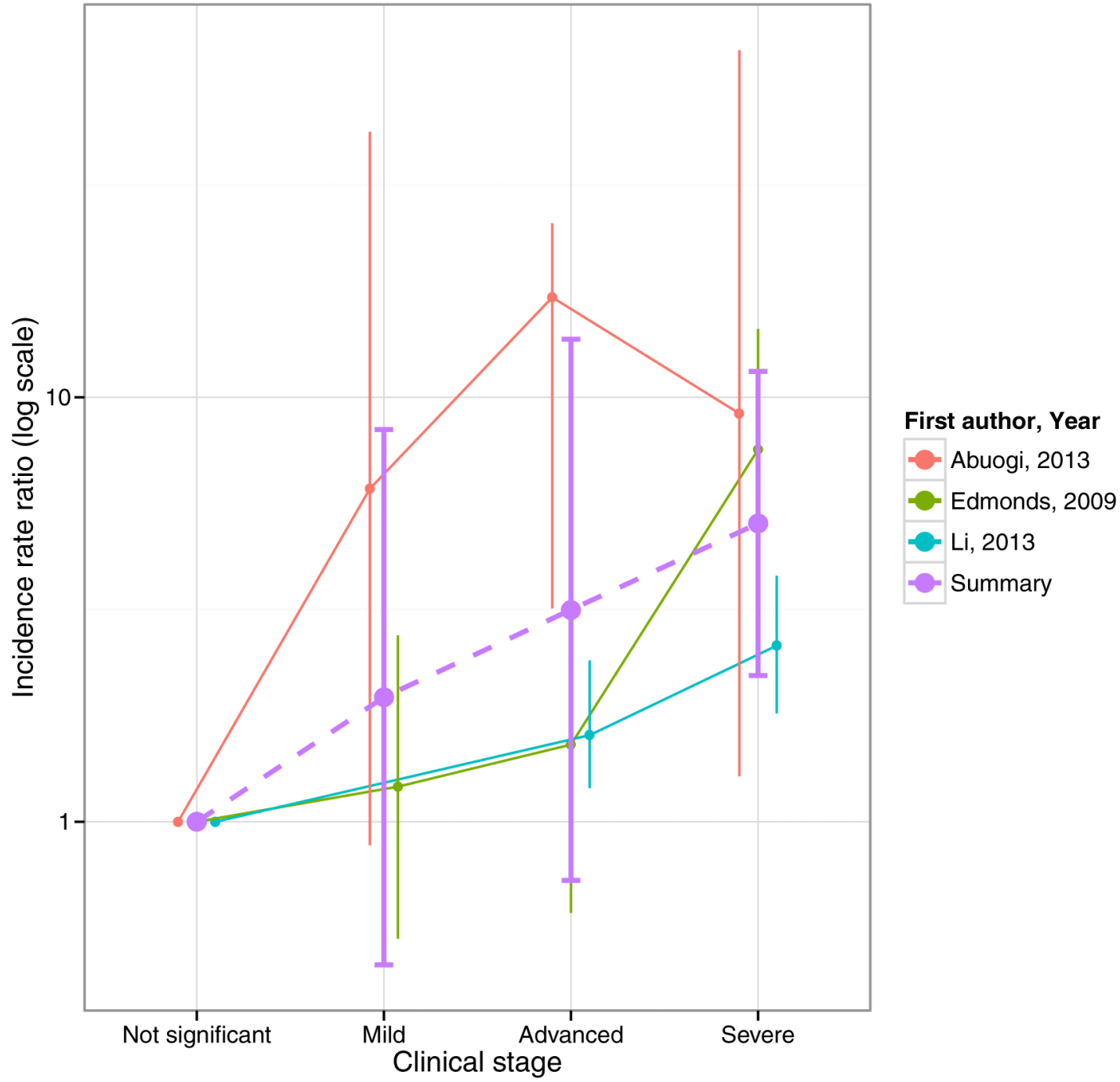

Figure 4 Relative TB incidence in children aged $<15$ years with HIV by WHO immunological staging $\left(I^{2}=87.1 \%\right)$.

Many studies allowed for unmasking of prevalent TB at ART initiation by excluding a certain period after initiation from comparisons, but this varied between studies. However, excluding all children diagnosed with TB soon after initiating ART may underestimate early incident TB in children who are still highly immunosuppressed. Only three HIV cohorts reported co-trimoxazole use, ${ }^{14} 67{ }^{80}$ but as guidelines have varied over time and by setting, co-trimoxazole use may have been underreported. Confounding by indication was not considered in estimates of ART protection (except for Edmonds et $a l^{70}$ ), and choice of covariates varied between studies. Our direct meta-analysis of the protective effect of ART was not able to include how long children had been on ART, and will average over the different distribution of treatment durations between studies.

We were not able to analyse age effects on TB, as data were seldom reported with multiple age stratifications. Our analysis of protection by time-on-ART may be confounded by age. Young children have particularly high TB progression risk, in part due to immature cell-mediated immune responses. ${ }^{1}$ The impact of age on efficacy of ART is also complex, as early ART initiation, at a better baseline immune status, leads to better immune reconstitution (although adherence can be challenging at the youngest ages due to a paucity of palatable formulations). ${ }^{83} 8788$ The studies in our review were conducted over years when ART treatment guidelines, availability and formulations were evolving. The relevance of our findings to current universal treatment recommendations needs careful consideration; individual patient data meta-analysis would be highly informative on the impact of host characteristics on risk of TB, in particular the age of the child and age at which ART was initiated. As children are started on ART at higher CD4 values, the protective benefit of ART against TB may be lower.

Despite these limitations, internal consistency between results from different analyses increases the confidence in our conclusions. Our IRR from TB cohorts is comparable with the estimate of 'severe' compared with 'not significant' immune staging, recognising that HIV may confer an increased risk of TB even before immunosuppression is clinically evident. The mean IRR over a range of CD4\% between $0 \%$ and $50 \%$ was 7.1 using the risk gradient point-estimate from our $\mathrm{CD} 4$ analysis-close to our IRR estimate for all HIV from TB cohorts. The mean protection against TB over the first 30 months on ART was 0.25 comparable to our meta-analysis of estimates of protection (although these analyses ultimately stem from the same data). The decline in TB rates by time-on-ART occurred on a similar timescale to the analysis presented by Li et al, ${ }^{73}$ although to a lower final value. Comparing our HIV and ART risk results 
Figure 5 Forest plot for meta-analysis of relation between incidence rate ratio for TB incidence and $\mathrm{CD} 4 \%$ in children aged $<15$ years.

Figure 6 Forest plot of protection on antiretroviral therapy against TB incidence in children $<15$ years with HIV infection $\left(I^{2}=79.0 \%\right)$. RE, random effects.

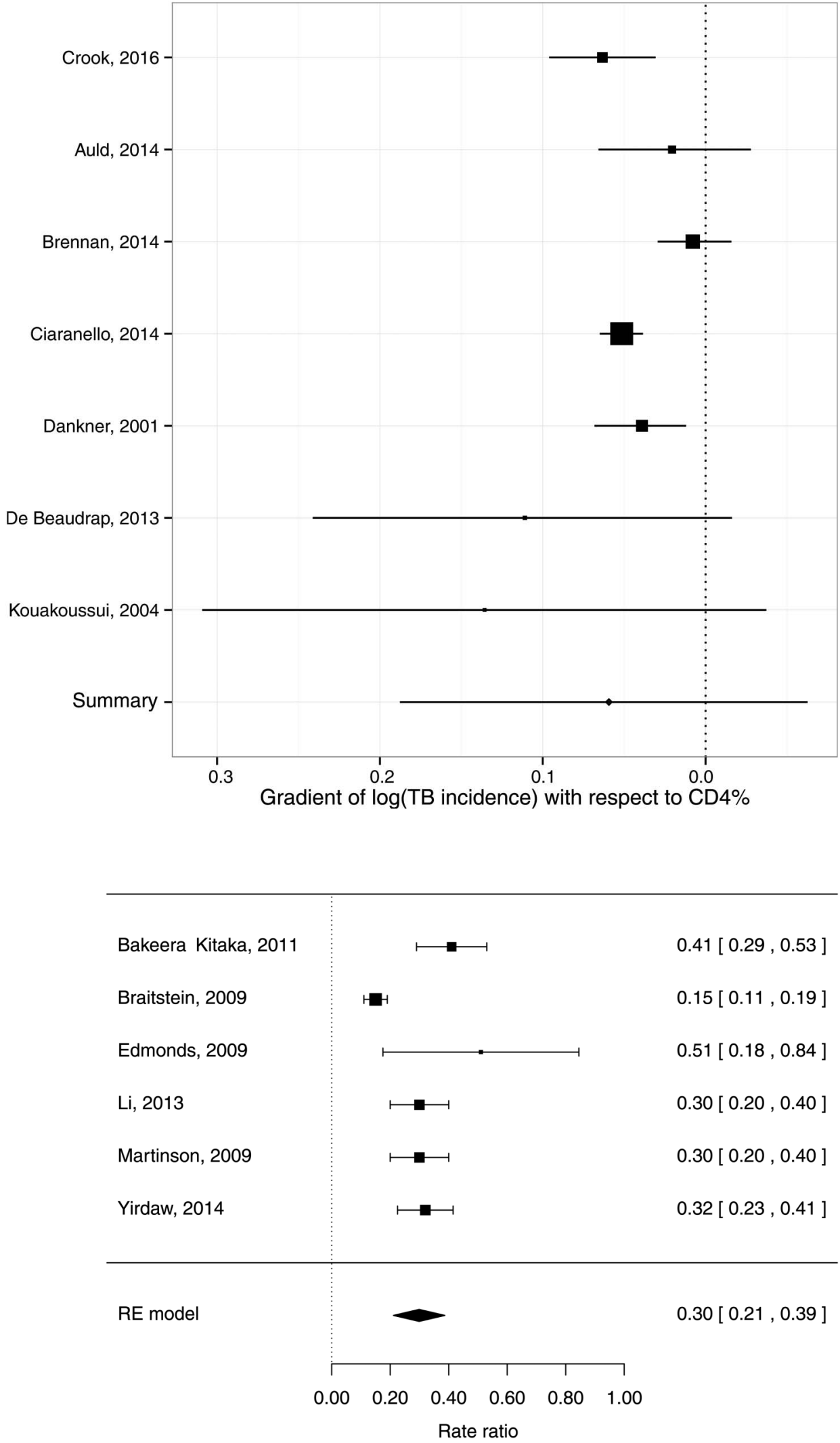

Rate ratio

suggests that children commencing ART are at higher risk of TB than HIV-uninfected children initially, but our results are too uncertain to specify whether long-term TB risks ART return to those of an HIV-uninfected child. For adults, TB risks established on long-term ART remain elevated over those of HIV-uninfected individuals. ${ }^{82}$
It is important to place ART in the context of other public health interventions. Our results suggest early diagnosis of infants and young children with HIV, followed by immediate ART, will reduce the pool of highly susceptible children and consequent progression to $\mathrm{TB}$ disease, providing further impetus to scale-up coverage among paediatric ART 


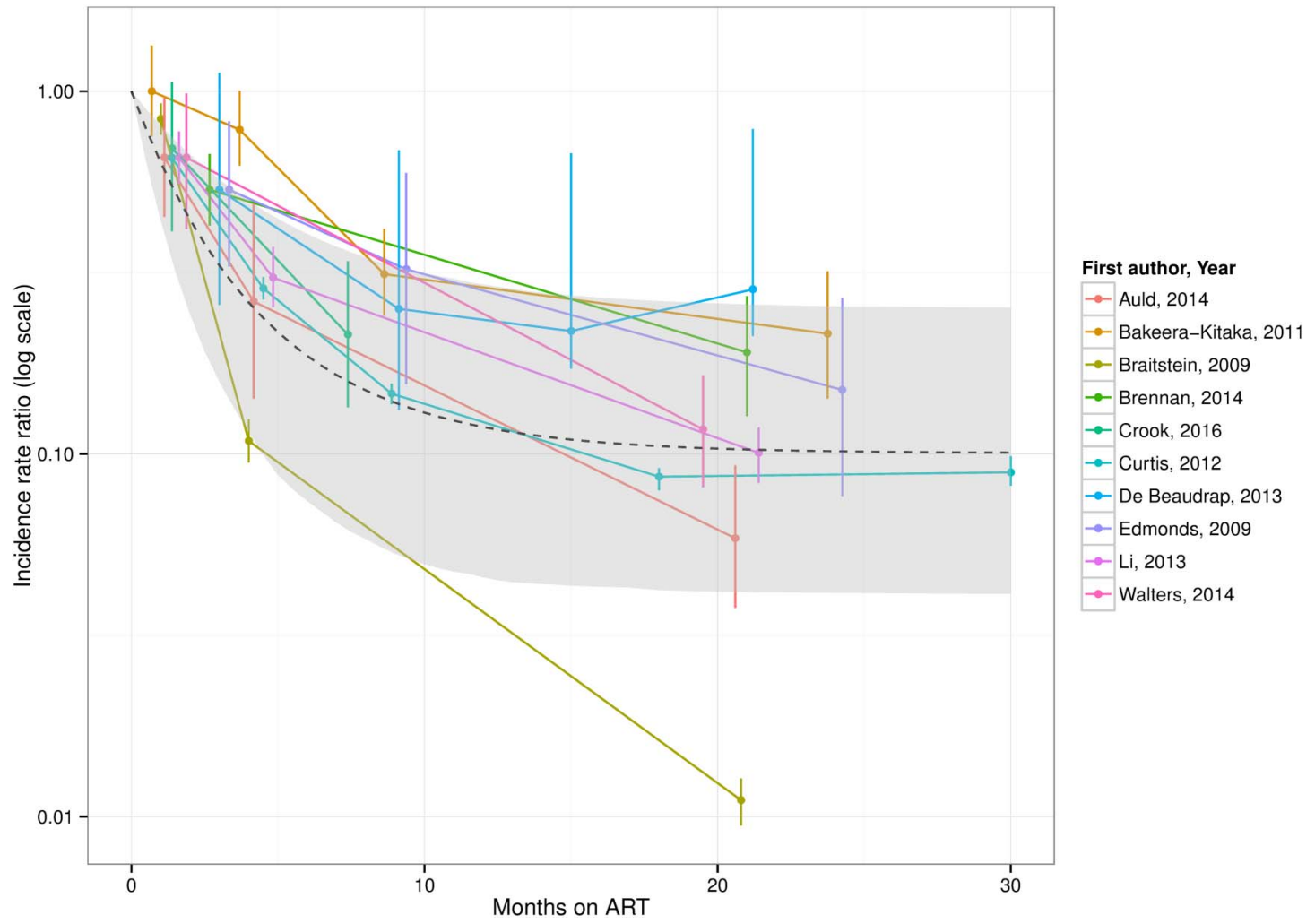

Figure 7 Meta-regression of protection from TB incidence in children $<15$ years by time-on-antiretroviral therapy (ART), and realigned incidence estimates from studies.

programmes. High HIV prevalence in the TB cohorts and high TB incidence in the HIV cohorts suggest that all children diagnosed with TB should be tested for HIV infection and all children with HIV should be regularly screened for TB disease. Scale-up of PMTCT will lead to fewer children becoming infected with HIV and is likely to be one of the most effective public health strategies to reduce paediatric HIV/TB; similarly, prompt diagnosis of TB in HIV-infected adults will reduce the risk of TB transmission to their HIV-infected children. TB control in adults more generally, ${ }^{89}$ and infection control measures, will reduce the risk of TB transmission to vulnerable children. IPT appears similarly effective at reducing TB incidence in HIV-infected children (around 70\% reduction in incidence), ${ }^{71} 80$ and evidence suggests that use in conjunction with ART is more protective than either intervention alone. ${ }^{90}$ Evidence for the benefit of co-trimoxazole in preventing incident TB in children is emerging; ${ }^{14}$ since it is now recommended long-term, co-trimoxazole prophylaxis may also help to reduce TB incidence among HIV-infected children on ART. Improving nutritional status among HIV-infected children may also be beneficial, as there is a high risk of TB in the context of malnutrition. Although individually these interventions are likely less effective than ART, their combination can be expected to protect the biggest number of children from developing TB.

\section{CONCLUSIONS}

Our results indicate that HIV infection is a potent risk factor for TB in children, with a gradient of risk by indices of immunosuppression. ART is strongly protective against TB in children with HIV infection, taking up to 2 years for protection to become fully established, underscoring the importance of prompt ART initiation.

\section{Twitter Follow Claire Beecroft @mscihta}

Contributors Conceived and designed the study; undertook the review and data abstraction; drafted article: PJD, JAS. Designed the search strategy: CB, PJD, JAS. Statistical analysis: PJD. Commented on and revised article: all authors.

Funding Study funded by the STEP TB UNITAID grant to TB Alliance. The funders had no role in the design or execution of the study, nor the decision to publish. BK is funded by a programme grant from the MRC. AJP is funded by the Wellcome Trust (108065/Z/15/Z).

Competing interests None declared.

Provenance and peer review Not commissioned; externally peer reviewed.

Data sharing statement All data used in the analyses are available either in the main article or the online supplementary materials.

Open Access This is an Open Access article distributed in accordance with the terms of the Creative Commons Attribution (CC BY 4.0) license, which permits others to distribute, remix, adapt and build upon this work, for commercial use, provided the original work is properly cited. See: http://creativecommons.org/licenses/ by/4.0/

\section{REFERENCES}

1 Marais BJ, Gie RP, Schaaf HS, et al. The natural history of childhood intra-thoracic tuberculosis: a critical review of literature from the pre-chemotherapy era. Int J Tuberc Lung Dis 2004;8:392-402.

2 Dodd PJ, Gardiner E, Coghlan R, et al. Burden of childhood tuberculosis in 22 high-burden countries: a mathematical modelling study. Lancet Glob Health 2014;2: e453-9.

3 World Health Organization. Global tuberculosis report 2015. Geneva, 2015.

4 UNAIDS. 2014 progress report on the global plan. Geneva, 2014

5 Tobin NH, Aldrovandi GM. Immunology of pediatric HIV infection. Immunol Rev 2013;254:143-69.

6 World Health Organization. Guidelines on when to start antiretroviral therapy and pre-exposure prophylaxis for HIV. Geneva: WHO, 2015

7 Corbett EL, Watt CJ, Walker N, et al. The growing burden of tuberculosis: global trends and interactions with the HIV epidemic. Arch Intern Med 2003;163:1009.

8 Williams BG, Dye C. Antiretroviral drugs for tuberculosis control in the era of HIV/ AIDS. Science 2003:301:1535-7. 
9 Williams BG, Granich R, De Cock KM, et al. Antiretroviral therapy for tuberculosis control in nine African countries. Proc Natl Acad Sci USA 2010;107:19485-9.

10 Suthar AB, Lawn SD, del Amo J, et al. Antiretroviral therapy for prevention of tuberculosis in adults with HIV: a systematic review and meta-analysis. PLoS Med 2012;9:e1001270.

11 Pretorius C, Menzies NA, Chindelevitch L, et al. The potential effects of changing HIV treatment policy on tuberculosis outcomes in South Africa: results from three tuberculosis-HIV transmission models. AIDS 2014;28(Suppl 1):S25-34.

12 Williams BG, Granich R, Chauhan LS, et al. The impact of HIV/AIDS on the control of tuberculosis in India. Proc Natl Acad Sci USA 2005;102:9619-24.

13 Moher D, Liberati A, Tetzlaff J, et al. Preferred reporting items for systematic reviews and meta-analyses: the PRISMA statement. Ann Intern Med 2009;151:264-9.

14 Crook AM, Turkova A, Musiime V, et al. Tuberculosis incidence is high in HIV-infected African children but is reduced by co-trimoxazole and time on antiretroviral therapy. BMC Med 2016;14:50.

15 Wells GA, Shea B, O'connell D, et al. The Newcastle-Ottawa Scale (NOS) for assessing the quality of nonrandomised studies in meta-analyses, 2000. http:// www.ohri.ca/programs/clinical_epidemiology/oxford.htm (accessed 1 Jan 2008).

16 Viechtbauer W. Conducting meta-analyses in R with the metafor package. J Stat Soft 2010;36:1-48

17 Jaganath $\mathrm{D}$, Zalwango $\mathrm{S}$, Okware $\mathrm{B}$, et al. Contact investigation for active tuberculosis among child contacts in Uganda. Clin Infect Dis 2013;57:1685-92.

18 Ade S, Harries AD, Trébucq A, et al. The burden and outcomes of childhood tuberculosis in Cotonou, Benin. Public Health Action 2013:3:15-19.

19 Berggren Palme I, Gudetta B, Bruchfeld J, et al. Detection of Mycobacterium tuberculosis in gastric aspirate and sputum collected from Ethiopian HIV-positive and HIV-negative children in a mixed in- and outpatient setting. Acta Paediatr 2004;93:311-15.

20 Berggren Palme I, Gudetta B, Degefu H, et al. A controlled estimate of the risk of HIV infection in Ethiopian children with tuberculosis. Epidemiol Infect 2001;127:517-25.

21 Bhat GJ, Diwan VK, Chintu C, et al. HIV, BCG and TB in children: a case control study in Lusaka, Zambia. J Trop Pediatr 1993;39:219-23.

22 Bobossi-Serengbe G, Tembeti PJ, Mobima T, et al. [Tuberculosis and HIV co-infection among children hospitalized in Bangui (Central African Republic)]. Arch Pediatr 2005;12:1215-20.

23 Campos-Herrero Navas MI, Rodriguez Villalobos H, Perera Gonzalez A, et al. [Tuberculosis en pediatric patients in the island of Gran Canaria]. An Esp Pediatr 1997:46:561-4.

24 Cathebras $\mathrm{P}$, Vohito JA, Yete ML, et al. [Tuberculosis and human immunodeficiency virus infection in the Central African Republic]. Med Trop (Mars) 1988:48:401-7.

25 Chintu C, Bhat G, Luo C, et al. Seroprevalence of human immunodeficiency virus type 1 infection in Zambian children with tuberculosis. Pediatr Infect Dis J 1993:12:499-504.

26 Chintu C, Dupont HL, Kaile T, et al. Human immunodeficiency virus-associated diarrhea and wasting in Zambia: selected risk factors and clinical associations. Am J Trop Med Hyg 1998;59:38-41.

27 Chintu C, Luo C, Bhat G, et al. Impact of the human immunodeficiency virus type-1 on common pediatric illnesses in Zambia. J Trop Pediatr 1995;41:348-53.

28 Daniel OJ, Ogunfowora OB, Oladapo OT. HIV sero-prevalence among children diagnosed with TB in Nigeria. Trop Doct 2007;37:268-9.

29 Edwards DJ, Kitetele F, Van Rie A. Agreement between clinical scoring systems used for the diagnosis of pediatric tuberculosis in the HIV era. Int I Tuberc Lung Dis 2007:11:263-9.

30 Espinal MA, Reingold AL, Perez $G$, et al. Human immunodeficiency virus infection in children with tuberculosis in Santo Domingo, Dominican Republic: prevalence, clinical findings, and response to antituberculosis treatment. J Acquir Immune Defic Syndr Hum Retrovirol 1996;13:155-9.

31 Feldacker $\mathrm{C}$, Tweya $\mathrm{H}$, Keiser $\mathrm{O}$, et al. Characteristics of adults and children diagnosed with tuberculosis in Lilongwe, Malawi: findings from an integrated HIV/ TB clinic. Trop Med Int Health 2012;17:1108-16.

32 Gava C, Malacarne J, Rios DPG, et al. Tuberculosis in indigenous children in the Brazilian Amazon. Rev Saude Publica 2013:47:77-85.

33 Geoghagen M, Farr JA, Hambleton I, et al. Tuberculosis and HIV co-infections in Jamaican children. West Indian Med J 2004;53:339-45.

34 Henegar C, Behets F, Vanden Driessche K, et al. Impact of HIV on clinical presentation and outcomes of tuberculosis treatment at primary care level. Int J Tuberc Lung Dis 2013:17:1411-13.

35 Hesseling AC, Cotton MF, Jennings $T$, et al. High incidence of tuberculosis among HIV-infected infants: evidence from a South African population-based study highlights the need for improved tuberculosis control strategies. Clin Infect Dis 2009:48:108-14

36 Hussain T, Sinha S, Talan S, et al. Seroprevalence of HIV infection among paediatric tuberculosis patients in Agra, India: a hospital-based study. Tuberculosis (Edinb) 2007:87:7-11

37 Iriso R, Mudido PM, Karamagi C, et al. The diagnosis of childhood tuberculosis in an HIV-endemic setting and the use of induced sputum. Int J Tuberc Lung Dis 2005;9:716-26.
38 Jain SK, Ordonez A, Kinikar A, et al. Pediatric tuberculosis in young children in India: a prospective study. Biomed Res Int 2013;2013:783698.

39 Jensen J, Álvaro-Meca A, Micheloud D, et al. Reduction in mycobacterial disease among HIV-infected children in the highly active antiretroviral therapy era (1997-2008). Pediatr Infect Dis J 2012;31:278-83.

40 Llerena C, Fadul SE, Garzón MC, et al. [Drug-resistant Mycobacterium tuberculosis in children under 15 years]. Biomedica 2010;30:362-70.

41 Luo C, Chintu C, Bhat G, et al. Human immunodeficiency virus type-1 infection in Zambian children with tuberculosis: changing seroprevalence and evaluation of a thioacetazone-free regimen. Tuber Lung Dis 1994;75:110-15.

42 Madhi SA, Gray GE, Huebner RE, et al. Correlation between CD4+ lymphocyte counts, concurrent antigen skin test and tuberculin skin test reactivity in human immunodeficiency virus type 1-infected and -uninfected children with tuberculosis. Pediatr Infect Dis J 1999;18:800-5.

43 Mehta S, Mugusi FM, Bosch RJ, et al. A randomized trial of multivitamin supplementation in children with tuberculosis in Tanzania. Nutr J 2011;10:120.

44 Miranda AE, Dietze R, Maciel EL, et al. Tuberculosis and AIDS co-morbidity in children: linkage of databases from Espirito Santo State, Brazil. J Trop Pediatr 2011;57:296-8.

45 Mukadi YD, Wiktor SZ, Coulibaly IM, et al. Impact of HIV infection on the development, clinical presentation, and outcome of tuberculosis among children in Abidjan, Cote d'Ivoire. AIDS 1997;11:1151-8.

46 Berggren Palme I, Gudetta B, Bruchfeld J, et al. Impact of human immunodeficiency virus 1 infection on clinical presentation, treatment outcome and survival in a cohort of Ethiopian children with tuberculosis. Pediatr Infect Dis J 2002:21:1053-61.

47 Panigatti $\mathrm{P}$, Ratageri VH, Shivanand I, et al. Profile and outcome of childhood tuberculosis treated with DOTS—an observational study. Indian J Pediatr 2014;81:9-14.

48 Rachow A, Clowes P, Saathoff E, et al. Increased and expedited case detection by Xpert MTB/RIF assay in childhood tuberculosis: a prospective cohort study. Clin Infect Dis 2012:54:1388-96.

49 Ramos JM, Reyes F, Tesfamariam A. Childhood and adult tuberculosis in a rural hospital in Southeast Ethiopia: a ten-year retrospective study. BMC Public Health 2010;10:215.

50 Rose MV, Kimaro G, Nissen TN, et al. QuantiFERON-TB gold in-tube performance for diagnosing active tuberculosis in children and adults in a high burden setting. PLOS ONE 2012;7:e37851

51 Sassan-Morokro M, De Cock KM, Ackah A, et al. Tuberculosis and HIV infection in children in Abidjan, Cote d'Ivoire. Trans R Soc Trop Med Hyg 1994;88:178-81.

52 Schaaf HS, Hesseling AC, Rautenbach C, et al. Trends in childhood drug-resistant tuberculosis in South Africa: a window into the wider epidemic? Int J Tuberc Lung Dis 2014;18:770-3.

53 Seddon JA, Hesseling AC, Marais BJ, et al. The evolving epidemic of drug-resistant tuberculosis among children in Cape Town, South Africa. Int J Tuberc Lung Dis 2012:16:928-33.

54 Shahab T, Zoha MS, Malik MA, et al. Prevalence of human immunodeficiency virus infection in children with tuberculosis. Indian Pediatr 2004:41:595-9.

55 Thomas TA, Heysell SK, Moodley P, et al. Intensified specimen collection to improve tuberculosis diagnosis in children from Rural South Africa, an observational study. BMC Infect Dis 2014;14:11.

56 Yassin MA, Petrucci R, Garie KT, et al. Can interferon-gamma or interferon-gamma-induced-protein-10 differentiate tuberculosis infection and disease in children of high endemic areas? PLOS ONE 2011;6:e23733.

57 Kwara A, Enimil A, Gillani FS, et al. Pharmacokinetics of first-line antituberculosis drugs using WHO revised dosage in children with tuberculosis with and without HIV coinfection. J Pediatr Infect Dis Soc 2016:5:356-65.

58 López-Varela E, Augusto 0 , Gondo K, et al. Incidence of tuberculosis in children under the age of three in Manhiça, rural southern Mozambique. Pediatr Infect Dis $J$ 2015;34:686-92.

59 Perfura Yone EW, Mbarga AE, Kuaban C. Impact de I'infection à VIH sur la tuberculose de l'enfant à Yaoundé, Cameroun. Rev Mal Respir 2012;29:1095-103.

60 Abuogi LL, Mwachari C, Leslie HH, et al. Impact of expanded antiretroviral use on incidence and prevalence of tuberculosis in children with HIV in Kenya. Int I Tuberc Lung Dis 2013;17:1291-7.

61 Alarcón JO, Freimanis-Hance L, Krauss M, et al. Opportunistic and other infections in HIV-infected children in Latin America compared to a similar cohort in the United States. AIDS Res Hum Retroviruses 2012:28:282-8.

62 Auld AF, Tuho MZ, Ekra KA, et al. Tuberculosis in human immunodeficiency virus-infected children starting antiretroviral therapy in Cote d'Ivoire. Int I Tuberc Lung Dis 2014;18:381-7.

63 Bakeera-Kitaka S, Conesa-Botella A, Dhabangi A, et al. Tuberculosis in human immunodeficiency virus infected Ugandan children starting on antiretroviral therapy. Int J Tuberc Lung Dis 2011;15:1082-6.

64 Braitstein $\mathrm{P}$, Nyandiko W, Vreeman $\mathrm{R}$, et al. The clinical burden of tuberculosis among human immunodeficiency virus-infected children in Western Kenya and the impact of combination antiretroviral treatment. Pediatr Infect Dis J 2009:28:626-32.

65 Brennan AT, Maskew M, Schnippel K, et al. Risk factors associated with TB in children receiving ART in a South African multicenter HIV cohort. Top Antivir Med 2014;22:484-5 
66 Ciaranello A, Lu Z, Ayaya S, et al. Incidence of World Health Organization stage 3 and 4 events, tuberculosis and mortality in untreated, HIV-infected children enrolling in care before 1 year of age: an leDEA (International Epidemiologic Databases To Evaluate AIDS) east Africa regional analysis. Pediatr Infect Dis I 2014;33:623-9.

67 Curtis AJ, Marshall CS, Spelman T, et al. Incidence of WHO stage 3 and 4 conditions following initiation of anti-retroviral therapy in resource limited settings. PLOS ONE 2012:7:e52019.

68 Dankner WM, Lindsey JC, Levin MJ, Pediatric ACTGPT. Correlates of opportunistic infections in children infected with the human immunodeficiency virus managed before highly active antiretroviral therapy. Pediatr Infect Dis J 2001:20:40-8.

69 De Beaudrap P, Boullé C, Lewden C, et al. Morbidity after antiretroviral therapy initiation in HIV-1-infected children in West Africa: temporal trends and relation to CD4 count. Pediatr Infect Dis J 2013;32:354-60.

70 Edmonds A, Lusiama J, Napravnik S, et al. Anti-retroviral therapy reduces incident tuberculosis in HIV-infected children. Int J Epidemiol 2009;38:1612-21.

71 Gray DM, Workman LJ, Lombard CJ, et al. Isoniazid preventive therapy in HIV-infected children on antiretroviral therapy: a pilot study. Int I Tuberc Lung Dis 2014; 18:322-7.

72 Kouakoussui A, Fassinou P, Anaky MF, et al. Respiratory manifestations in HIV-infected children pre- and post-HAART in Abidjan, the Ivory Coast. Paediatr Respir Rev 2004;5:311-15.

73 Li N, Manji KP, Spiegelman D, et al. Incident tuberculosis and risk factors among HIV-infected children in Tanzania. AIDS 2013;27:1273-81.

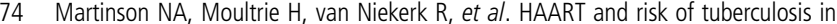
HIV-infected South African children: a multi-site retrospective cohort. Int I Tuberc Lung Dis 2009;13:862-7.

75 Prasitsuebsai W, Kariminia A, Puthanakit T, et al. Impact of antiretroviral therapy on opportunistic infections of HIV-infected children in the therapeutic research, education and AIDS training Asia pediatric HIV observational database. Pediatr Infect Dis J 2014;33:747-52.

76 Thomas P, Bornschlegel K, Singh TP, et al. Tuberculosis in human immunodeficiency virus-infected and human immunodeficiency virus-exposed children in New York City. The New York City Pediatric Spectrum of HIV Disease Consortium. Pediatr Infect Dis / 2000;19:700-6.

77 Walters E, Cotton MF, Rabie H, et al. Clinical presentation and outcome of tuberculosis in human immunodeficiency virus infected children on anti-retroviral therapy. BMC Pediatr 2008;8:1.
78 Walters E, Duvenhage J, Draper HR, et al. Severe manifestations of extrapulmonary tuberculosis in HIV-infected children initiating antiretroviral therapy before 2 years of age. Arch Dis Child 2014;99:998-1003.

79 Yirdaw KD, Jerene D, Gashu Z, et al. Beneficial effect of isoniazid preventive therapy and antiretroviral therapy on the incidence of tuberculosis in people living with HIV in Ethiopia. PLoS ONE 2014;9:e104557.

80 Zar HJ, Cotton MF, Strauss S, et al. Effect of isoniazid prophylaxis on mortality and incidence of tuberculosis in children with HIV: randomised controlled trial. BMJ 2007;334:136.

81 Lawn SD, Myer L, Edwards D, et al. Short-term and long-term risk of tuberculosis associated with CD4 cell recovery during antiretroviral therapy in South Africa. AIDS 2009:23:1717-25.

82 Gupta A, Wood R, Kaplan R, et al. Tuberculosis incidence rates during 8 years of follow-up of an antiretroviral treatment cohort in South Africa: comparison with rates in the community. PLOS ONE 2012;7:e34156.

83 Picat MQ, Lewis J, Musiime V, et al. Predicting patterns of long-term CD4 reconstitution in HIV-infected children starting antiretroviral therapy in sub-Saharan Africa: a cohort-based modelling study. PLoS Med 2013;10:e1001542.

84 García F, de Lazzari E, Plana M, et al. Long-term CD4+ T-cell response to highly active antiretroviral therapy according to baseline CD4+ T-cell count. J Acquir Immune Defic Syndr 2004;36:702-13.

85 Moore RD, Keruly JC. CD4+ cell count 6 years after commencement of highly active antiretroviral therapy in persons with sustained virologic suppression. Clin Infect Dis 2007:44:441-6.

86 Jenkins $\mathrm{HE}$, Yuen $\mathrm{CM}$, Rodriguez $\mathrm{CA}$, et al. Mortality among children diagnosed with tuberculosis: Systematic review and meta-analysis. Lancet Infect Dis. Published

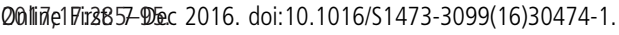

87 Bamford A, Turkova A, Lyall H, et al. Paediatric European Network for Treatment of AIDS (PENTA) guidelines for treatment of paediatric HIV-1 infection 2015: optimizing health in preparation for adult life. HIV Med Published Online First: 3 Feb 2015. doi:10.1111/hiv.12217.

88 Lewis J, Walker AS, Castro H, et al. Age and CD4 count at initiation of antiretroviral therapy in HIV-infected children: effects on long-term T-cell reconstitution. J Infect Dis 2012;205:548-56.

89 Denkinger CM, Kampmann B, Ahmed S, et al. Modeling the impact of novel diagnostic tests on pediatric and extrapulmonary tuberculosis. BMC Infect Dis 2014;14:477.

90 Frigati LJ, Kranzer K, Cotton MF, et al. The impact of isoniazid preventive therapy and antiretroviral therapy on tuberculosis in children infected with HIV in a high tuberculosis incidence setting. Thorax 2011;66:496-501. 